\title{
Correspondence
}

\section{The correct paradigm may be that of evolutionary psychiatry}

Dr Thomas Szasz repeats his view that psychiatric illness does not exist, and that people should be held responsible for their beliefs and actions. ${ }^{1}$ But what if we are presented with a mother who believes she has committed an unforgivable sin, and that she and her baby are infested with the devil, with the only solution being to kill herself and her child? We know that with treatment, or just with the passage of time, she will return to normal and realise that her 'sinfulness' was delusional. As I understand Dr Szasz, he would consider treating her to be 'a grave violation of her basic human rights' and he would advise us to let her 'minister to herself'. Yet does she not have a basic human right to be treated, even if she has no insight into her need for treatment?

It is likely that evolution has prepared mental states for extreme situations and that it is possible to enter one either because a person is in an extreme situation, or by mistake, on the 'smoke detector' principle that it is better to be frightened to death a hundred times thinking there is a lion in the bush rather than ignore one real clue that a lion really is there. ${ }^{2}$ It may be impossible to tell whether a mental state is caused by a real danger or disaster, or is due to a psychic mistake. A depressed mother with a baby may be a member of one of those societies who try to maintain a constant population, whose surplus men go into monasteries and only one daughter per family is allowed to breed, and she may have offended against society's rules by getting pregnant outside marriage. In the Book of Job, Job lost his children and all his cattle and became depressed, but why did his so-called comforters not offer their condolences on the death of his children? This may suggest that the text can be as easily read as a story of a man who, owing to psychotic depression, had the delusion of loss of property and death of loved ones. ${ }^{3}$ In psychiatric practice we are often dealing with people who have entered states of depression and anxiety when there is no real cause - are we not to help them?

The paradigm here is evolutionary psychiatry. ${ }^{4}$ It is not necessary to view these deluded and anxious people as either sinful or responsible - whether or not we treat them as 'sick' depends on factors such as eligibility for NHS healthcare and other practical matters. We have been fashioned by evolution to suffer inappropriate extremes of mental pain and delusional ideas - it is more important to help these people back to normality than to spend time discussing whether they are sick or bad or should bear responsibility for themselves.

I must acknowledge one debt to Dr Szasz. In my long career in working age psychiatry, I was often asked by troubled patients what to say when, applying for a job, they were asked whether they had ever had mental illness. Knowing of the stigma and prejudice that a positive answer would probably arouse, I was able to say to them with a clear conscience, 'Think Szasz and say 'No!'.'

1 Szasz T. The myth of mental illness: 50 years later. Psychiatrist 2011; 35: 179-82.
2 Nesse RM. Natural selection and the regulation of defences: a signal detection analysis of the smoke detector principle. Evol Hum Behav 2005; 26: 88-105.

3 Price JS, Gardner Jr R. Does submission to a deity relieve depression? Illustrations from the Book of Job and the Bhagavad Gita. Philosophical Paper Rev 2009; 1: 017-31.

4 Bruene M. Textbook of Evolutionary Psychiatry: The Origins of Psychopathology. Oxford University Press, 2008.

John S. Price is a retired consultant psychiatrist. Correspondence c/o The Psychiatrist Editorial Office, Royal College of Psychiatrists, 17 Belgrave Square, London SW1X 8PG, UK, email: johnscottprice@hotmail.com doi: $10.1192 / p b .35 .8 .314$

\section{Just the facts, please}

Edward Shorter's riposte to 'The myth of mental illness' cuts through the redundant reasoning of Szasz, in some style. ${ }^{1,2}$ Shorter succeeds by contrasting the notions of mental illness in the 1960s with modern science of the brain. In doing so, he also highlights the progression of psychiatry during this period. Unfortunately, his argument is undermined by unscientific claims. How many suicides resulted from anti-psychiatry? How many are due to One Flew Over the Cuckoo's Nest? Shorter says 'many'. If this is based on evidence, a reference should be cited. If not, why include conjecture in an otherwise excellent commentary?

1 Shorter E. Still tilting at windmills: Commentary on ... The myth of mental illness. Psychiatrist 2011; 35: 183-4.

2 Szasz T. The myth of mental illness: 50 years later. Psychiatrist 2011; 35: 179-82.

Thomas James Reilly is medical student, University of Aberdeen, Highland Medical Education Centre, Centre for Health Sciences, Old Perth Road, Inverness IV2 3JH, UK, email: t.j.reilly.06@aberdeen.ac.uk

doi: $10.1192 / \mathrm{pb} .35 .8 .314 a$

\section{III-mannered and ill-informed}

It is astonishing to read in The Psychiatrist the coarse, ignorant and abusive screed by Edward Shorter as a commentary on the 50th anniversary of Szasz's scholarly book, The Myth of Mental Illness.

The book contains 'bombast', Shorter declares, and 'cockeyed belligerence.' Portentously, Shorter explains that: 'in the way of its fraudulent notions', and those of the movie One Flew Over The Cuckoo's Nest, along with the anti-psychiatrist writings of Foucault, Laing and Cooper (who actually were quite unconnected with Szasz, his book, and the film) people decided not to seek psychiatric help and 'many died by suicide' instead for which the 'anti-psychiatry gurus' were therefore responsible.

Shorter cites no published evidence for this demonising of Szasz and the anti-psychiatrists and in fact there is none to cite. If this were not enough, Shorter goes on to make pronouncements about psychoanalysis, which he declares is dead. Does he mean dead in Toronto where he lives, or 